\title{
CELL FORMATION IN GROUP TECHNOLOGY: A SIMILARITY ORDER CLUSTERING APPROACH
}

\author{
Professor Godfrey C Onwubolu
}

\begin{abstract}
Grouping parts into families which can be produced by a cluster of machine cells is the cornerstone of cellular manufacturing, which in turn is the building block for flexible manufacturing systems. Cellular manufacturing is a group technology (GT) concept that has recently attracted the attention of manufacturing firms operating under jobshop environment to consider redesigning their manufacturing systems so as to take advantage of increased throughput, reduction in work-in-progress, set-up time, and lead times; leading to product quality and customer satisfaction. The paper presents a generalised approach for machine cell formation from a jobshop using similarity order clustering technique for preliminary cell grouping and considering machine utilisation for the design of nonintergrouping material handling using the single-pass heuristic. The work addresses the shortcomings of cellular manufacturing systems design and implementations which ignore machine utilisations, group sizes and intergroup moves.
\end{abstract}

Department of Industrial Engineering, National University of Science and Technology, Bulawayo, Zimbabwe 


\section{INTRODUCTION}

Many manufacturing firms which hitherto satisfied their customers while operating jobshop production systems have recently had to rethink because of the superiority of group technology (GT) philosophy of cellular manufacturing. Cellular manufacturing systems (CMS) house a large variety and combinations of processes and shorten manufacturing lead times, reduce work-in-progress (WIP), lower set-up times and operations costs, improve quality, increase workers job satisfaction and subsequent customer satisfaction [1]. Manufacturing firms which embrace modern manufacturing improvement philosophies such as just-in-time (JT), total quality management (TQM), business process re-engineering (BPR) and time-based competition (TBC) use the principles of CMS in their manufacturing system restructuring efforts so as to meet world-class manufacturing status [2].

Solving flexible manufacturing systems (FMS) optimal production planning and scheduling problems through size reduction requires grouping of parts into part families at aggregate planning level [3].

Planning and scheduling FMS at the disaggregate level involves machines, parts and additional components such as tools, fixtures, grippers and material handling components. The costs of these components are usually high and they. may be in limited quantities. Figure 1 shows the decomposition of FMS planning situation at disaggregation level, with all the parts to be manufactured and the associated components being decomposed into disjoint part and component families.

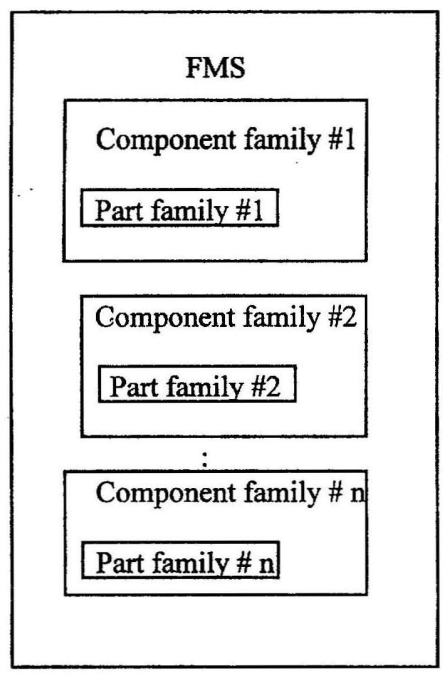

Figure 1: Decomposition of FMS planning at disaggregation level

This results in each of the individual part and component families being easier to manage. Individual part families are manufactured by machine groups which utilise associated components such as the tools, fixtures, grippers and material handling components already mentioned. 
The grouping problem in GT involves diagonalisation of a given machine-part incidence matrix into a cluster of machines which produce a cluster of parts. In FMS, the corresponding cluster of machines is referred to as flexible manufacturing cell (FMC), while at lower level in the classical GT physical cells, the cluster of machines is ordinarily referred to as manufacturing cell. Since manufacturing cell is the building block of FMC, the discussion in the remaining sections of this paper concentrate on machine and part families grouping without loss of generality.

\section{MACHINE CELL FORMATION TECHINIQUES}

Various approaches to cell formation have since been reported and may fall under one of the six major classifications: array-based clustering, similarity coefficient, mathematical programming, graph and network, heuristic and combinatorial optimisation.

There are two types of array-based clustering techniques; rank order clustering (ROC) and bond energy analysis (BEA). In ROC, a positional based value is assigned to each " 1 " in the machinepart incidence matrix and the values of all the "1"s in each row and each column are summed, the rows and columns being rearranged in decreasing order based on the values from top to bottom, and from left to right respectively [4]. This process is continued until an invariant matrix is obtained resulting in a clustering of machines and parts along the diagonal. Extensions to ROC to include cost data [5] and prevention of positional based value getting extremely large for large number of machines and parts [6] have been reported. Progressive slicing of identified group after one iteration of row ranking and one iteration of column ranking [7] have led to drastic improvement of $\mathrm{ROC}$ results. The bond energy which is defined as the product of the values of the adjoining row and column elements in the machine-part incidence matrix to determine the degree of clustering has been successfully implemented, with an optimal solution being one which maximises the bond energy [8].

The first work to use similarity measures to group machines and parts into cells [9] utilises a similarity matrix which contains all pairwise similarity coefficients between each machine. The similarity matrix obtained is then used by the single linkage clustering algorithm (SLCA) to form the machine groups. These methods have been adopted by other researchers [10] to [13]. The clustering algorithms based on similarity coefficient fall under two classifications: hierarchical and non-hierarchical. Both the single linkage clustering algorithm and the average clustering algorithm are hierarchical clustering algorithms. The only known non-hierarchical clustering reported so far include the MacQueen's k-means method [14] which requires the number of clusters to be specified in advance, the ideal-seed algorithm [15] and its improved version ZODIAC [16].

The p-median model based on an integer programming formulation which seeks to maximise the sum of similarity coefficients for a fixed number of groups with the constraints that a part will be assigned to not more than one family, has been used to solve the GT grouping problem [17]. Kusiak's similarity coefficients matrix has been used as input to an assignment model [18] to solve disjoint and non-disjoint part families problems. The part grouping problem in GT has been modelled as a linear transportation problem, solved in a two-phase algorithm to approximate the optimal solution [19]. The p-median formulation [20] is an integer programming model with an objective function which seeks to minimise the total sum of clusters-to-cluster median distances.

Kumar et al., [19] formulated the GT grouping problem as an optimal k-decomposition problem in graph theoretic terms in which decomposition of networks are considered rather than block diagonalisation of matrices. Lenstra [21] formulated the clustering of a two-dimensional data array as equivalent to solving two travelling salesman problem. This problem has been mapped as a kdecomposition of weighted networks which. 
Several heuristics which give polynomial bounds on the required computation time, but which do not guarantee optimal solution include [23], [24] and [25], to mention a few.

So far, existing standard cell formation models have been reviewed. However, these models ignore key factors such as machine utilisations, group sizes, and exceptional elements. This study describes a formulation based on similarity order clustering (SOC) for grouping of machines and parts [26] with the inclusion of single-pass heuristic to solve the problems inherent in standard cell formation models.

\section{GENERALISED MACHINE CELL FORMATION SCHEME}

The systematic method used in constructing the generalised machine cell formation used in this research work is shown in Figure 2. The steps involved are as follows:

1. A strategy for preliminary cell grouping using the similarity order clustering (SOC) scheme.

2. The preliminary cell grouping and base-data are used to determine machine utilisation. The minimum number of each machine is inferred from the machine utilisation consideration.

3. Design for non-intergrouping material handling using single-pass heuristic.

4. Implementation of final machine-cells.

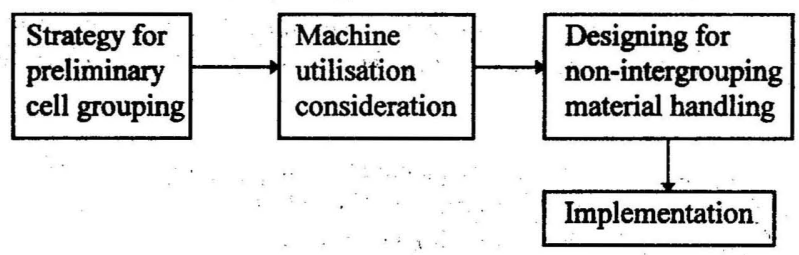

Figure 2: The approach

\section{STRATEGY FOR PRELIMINARY CELL GROUPING}

The formulated model for preliminary cell grouping uses the 0-1 machine-part incidence matrix as input and the Kusiak similarity coefficients matrices [17] for machines and parts as basis.

The four steps involved are as follows:

\subsection{SUBMIT 0 - 1 MACHINE-PART MATRIX TO SOC SCHEME}

The routing sheet from a jobshop production system is used for the input data. This is a simple twodimensional matrix with machine identifications in rows and parts which visit each machine for production entered in columns.

\subsection{GENERATION OF KUSIAK SIMILARITY COEFFICIENTS MATRICES FOR MACHINES AND PARTS}

Pairwise rows (machines) are compared bit-wise for similarity and the sum of all similar bits are summed up to give the similarity coefficient of the row (machine) - pair considered. Bits are similar if they are each " 1 " or " 0 ", otherwise the contribution is zero. The diagonal values are all zero. Off-diagonal coefficient values aretter. $\%$ saffe.jnteqfer 
generated for parts. These square matrices are easily used as input to computer packages for solving assignment, linear transportation and travelling salesman problems in linear programming.

\subsection{ARRANGE THE VALUES OF THE KUSIAK SIMILARITY MATRIX IN DESCENDING ORDER}

The square similarity coefficient matrix is scanned and the values are arranged in descending order. For the machine similarity coefficient matrice, the row and column indices which locate the values are stored in the topology matrix. A similarity topology matrix is obtained for the parts.

\subsection{MACHINE AND PARTS SEQUENCE LOGIC SCHEME}

The machines and parts sequences logic scheme uses the topology generated in Section 4.3 to obtain the sequences of machines and parts, which when used to rearrange the initial machine-incidence matrice gives clusters of machines and parts that enables the user to identify cell groups.

The operation routings information for a 9 machine-10 part problem in a jobshop which is to be redesigned to a manufacturing cell are shown in Table 1. The corresponding machine-incidence matrix is shown in Figure 3. Steps 1 to 4 (Sections 4.1 to 4.4 ) of the strategy for preliminary cell grouping give the machine cells in Figure 4.

Table 1: A $9 \times 10$ operation routing data

\begin{tabular}{|l|ll|}
\hline Part & Machine \\
\hline 1 & $\mathrm{M} 5 \longrightarrow \mathrm{M} 6 \longrightarrow \mathrm{M} 9$ \\
2 & $\mathrm{M} 1 \longrightarrow \mathrm{M} 3 \longrightarrow \mathrm{M} 8$ \\
3 & $\mathrm{M} 2 \longrightarrow \mathrm{M} 4 \longrightarrow \mathrm{M} 7$ \\
$\mathbf{4}$ & $\mathrm{M} 5 \longrightarrow \mathrm{M} 6 \longrightarrow \mathrm{M} 9$ \\
$\mathbf{5}$ & $\mathrm{M} 5 \longrightarrow \mathrm{M} 6 \longrightarrow \mathrm{M} 9$ \\
6 & $\mathrm{M} 1 \longrightarrow \mathrm{M} 3 \longrightarrow \mathrm{M} 8$ \\
7 & $\mathrm{M} 2 \longrightarrow \mathrm{M} 4 \longrightarrow \mathrm{M} 7$ \\
8 & $\mathrm{M} 5 \longrightarrow \mathrm{M} 6 \longrightarrow \mathrm{M} 9$ \\
9 & $\mathrm{M} 1 \longrightarrow \mathrm{M} 2 \longrightarrow \mathrm{M} 3 \longrightarrow \mathrm{M} 8$ \\
$\mathbf{1 0}$ & $\mathrm{M} 2 \longrightarrow \mathrm{M} 2 \longrightarrow \mathrm{M} 7$ \\
\hline
\end{tabular}

\begin{tabular}{|l|l|l|l|l|l|l|l|l|l|l|}
\hline \multirow{2}{*}{ Machine } & \multicolumn{10}{|c|}{ Part } \\
\cline { 2 - 13 } & 1 & 2 & 3 & 4 & 5 & 6 & 7 & 8 & 9 & 10 \\
\hline 1 & 0 & 1 & 0 & 0 & 0 & 1 & 0 & 0 & 1 & 0 \\
\hline 2 & 0 & 0 & 1 & 0 & 0 & 0 & 1 & 0 & 1 & 1 \\
\hline 3 & 0 & 1 & 0 & 0 & 0 & 1 & 0 & 0 & 1 & 0 \\
\hline 4 & 0 & 0 & 1 & 0 & 0 & 0 & 1 & 0 & 0 & 1 \\
\hline 5 & 1 & 0 & 0 & 1 & 1 & 0 & 0 & 1 & 0 & 0 \\
\hline 6 & 1 & 0 & 0 & 1 & 1 & 0 & 0 & 1 & 0 & 0 \\
\hline 7 & 0 & 0 & 1 & 0 & 0 & 0 & 1 & 0 & 0 & 1 \\
\hline 8 & 0 & 1 & 0 & 0 & 0 & 1 & 0 & 0 & 0 & 0 \\
\hline 9 & 1 & 0 & 0 & 1 & 1 & 0 & 0 & 1 & 1 & 0 \\
\hline
\end{tabular}

Figure 3: Machine-incidence matrix for Table 1

There are three machine cells having machines $\{1,3,8\},\{2,4,7\}$ and $\{5,6,9\}$. The associated part families are $\{6,2,9\},\{7,10,3\}$ and $\{4,1,5,8\}$ respectively. 


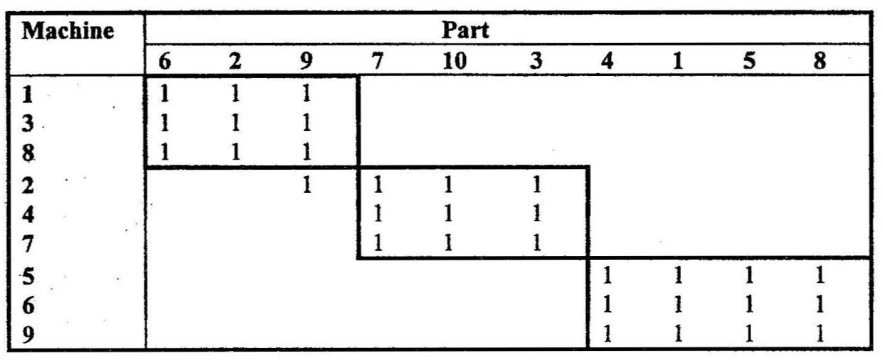

Figure 4: Preliminary cell grouping using SOC scheme

\section{MACHINE UTILISATION CONSIDERATION}

A standard model uses a binary incidence matrix and has solution of the form shown in Figure 4. It ignores several practical manufacturing factors such as group sizes, part demand, machine utilisations, and the cost of transporting a part between machine cells due to exceptional elements. Part 9 produced by machine 2 is an exceptional element which is now used to illustrate the drawback of the standard model. There are two possibilities in assigning part 9. If part 9 which is produced in machine 2 is extremely crucial to the product, then machine 2 has to be duplicated. Otherwise, part 9 may be produced outside the three cells.

The research work presented here, considers the manufacturing factors discussed in the paper: group sizes, part demand, machine utilisations and exceptional elements. To illustrate the machine utilisation consideration by the approach presented, the part demand, operation routings and process times for the 9-machine, 10 part problem already considered are shown in Table 2.

Table 2: Parts demand, operation routings and processing times

\begin{tabular}{|l|l|l|l|}
\hline $\begin{array}{l}\text { Part } \\
\mathbf{i}\end{array}$ & $\begin{array}{l}\text { Demand } \\
\mathbf{d}_{\mathbf{i}}\end{array}$ & Operation routings & $\begin{array}{l}\text { Processing time } \\
\mathbf{t}_{\mathbf{i}}\end{array}$ \\
\hline $\mathbf{1}$ & 2500 & $\mathrm{M} 5 \longrightarrow \mathrm{M} 6 \longrightarrow \mathrm{M} 9$ & $1,5,4$ \\
$\mathbf{2}$ & 3000 & $\mathrm{M} 1 \longrightarrow \mathrm{M} 3 \longrightarrow \mathrm{M} 8$ & $4,1,2$ \\
$\mathbf{3}$ & 2000 & $\mathrm{M} 2 \longrightarrow \mathrm{M} 4 \longrightarrow \mathrm{M} 7$ & $1,5,1$ \\
$\mathbf{4}$ & 1500 & $\mathrm{M} 5 \longrightarrow \mathrm{M} 6 \longrightarrow \mathrm{M} 9$ & $2,3,2$ \\
$\mathbf{5}$ & 2300 & $\mathrm{M} 5 \longrightarrow \mathrm{M} 6 \longrightarrow \mathrm{M} 9$ & $3,2,3$ \\
$\mathbf{6}$ & 2700 & $\mathrm{M} 1 \longrightarrow \mathrm{M} 3 \longrightarrow \mathrm{M} 8$ & $2,2,5$ \\
$\mathbf{7}$ & 3000 & $\mathrm{M} 2 \longrightarrow \mathrm{M} 4 \longrightarrow \mathrm{M} 7$ & $1,2,2$ \\
$\mathbf{8}$ & 2900 & $\mathrm{M} 5 \longrightarrow \mathrm{M} 6 \longrightarrow \mathrm{M} 9$ & $4,4,4$ \\
$\mathbf{9}$ & 2100 & $\mathrm{M} 1 \longrightarrow \mathrm{M} 2 \longrightarrow \mathrm{M} 3 \longrightarrow \mathrm{M} 8$ & $1,2,3,3$ \\
$\mathbf{1 0}$ & 1300 & $\mathrm{M} 2 \longrightarrow \mathrm{M} 4 \longrightarrow \mathrm{M} 7$ & $2,1,3$ \\
\hline
\end{tabular}

The intention here is to replace the 1's in the machine-part matrix of the preliminary cell grouping obtained using the SOC scheme with actual machine utilisations. The machine utilisation, $u$ is defined as:

$$
u_{i}=\left(t_{i m}+s_{i m} / q_{i}\right) d_{i} / a_{m}
$$


where $t_{i m}$ is the processing time for part $\mathrm{i}$ on machine type $\mathrm{m}$; $\mathrm{s}_{\mathrm{im}}$ is the setup time per batch obtained by adding part i setup time to its apportioned share of family setup; $\mathrm{q}_{\mathrm{i}}$ is the part batch sizes; $d_{i}$ is the period demand for part $i$; and $a_{m}$ is the time available per machine per period.

The base data for the problem under consideration are $s_{\mathrm{im}}=0.2, \mathrm{q}_{\mathrm{i}}=10, \mathrm{a}_{\mathrm{m}}=8$ (working hours per day) and period $=300$ working days per annum.

The period for the demands is one year and the unit for the processing is in hours. From Table 2 and the base-data the utilisation for machine 1 is obtained by summing the contributions made by parts 6,2 and 9 as shown in the first row of cell 1 in Figure 4:

$\begin{array}{lll}\text { Part } 6 \text { on machine } 1 \text { contribution } & = & (2+0.2 / 10) \times 2700 /(300 \times 8 \times 8) \\ & = & 0.284=0.3 \\ \text { Part } 2 \text { on machine } 1 \text { contribution } & = & (4+0.2 / 10) \times 3000 /(300 \times 8 \times 8) \\ & =0.628=0.6 \\ \text { Part } 9 \text { on machine } 1 \text { contribution } & =(1+0.2 / 10) \times 2100 /(300 \times 8 \times 8) \\ \text { Total utilisation for machine } 1 & =0.11=0.1 \\ & =0.3+0.6+0.1=1\end{array}$

The complete machine utilisation matrix is given in Figure 5. Summing across columns results in the total utilisation values for each machine row. The lower bound on the number of machines of each type is obtained by summing up each machine total utilisation values. The machine lower bound $m_{1}$ generated by the procedure described and the machine upper bound $m_{u}$ decided by the organisation are used by the decision rule for part assignment in the next section.

\begin{tabular}{|c|c|c|c|c|c|c|c|c|c|c|c|c|}
\hline \multirow{2}{*}{ Machine } & \multicolumn{10}{|c|}{ Part } & \multirow{2}{*}{$\begin{array}{l}\text { Total } \\
\text { Utilisation }\end{array}$} & \multirow{2}{*}{$\begin{array}{l}\text { Machine } \\
\text { Lower } \\
\text { Bound }\end{array}$} \\
\hline & 6 & 2 & 9 & 7 & 10 & 3 & 4 & 1 & 5 & 8 & & \\
\hline 1 & 0.3 & 0.6 & 0.1 & & & & & & & & 1 & 1 \\
\hline 3 & 0.3 & 0.2 & 0.3 & & & & & & & & 0.8 & 1 \\
\hline 8 & 0.7 & 0.3 & 0.3 & & & & & & & & 1.3 & 2 \\
\hline 2 & & & 0.2 & 0.2 & 0.1 & 0.1 & & & & & 0.6 & 1 \\
\hline 4 & & & & 0.3 & 0.1 & 0.5 & & & & & 0.9 & 1 \\
\hline 7 & & & & 0.3 & 0.2 & 0.1 & & & & & 0.6 & 1 \\
\hline 5 & & & & & & & 0.2 & 0.1 & 0.4 & 0.6 & 1.3 & 2 \\
\hline 6 & & & & & & & 0.2 & 0.7 & 0.2 & 0.6 & 1.7 & 2 \\
\hline 9 & & & & & & & 0.2 & 0.5 & 0.4 & 0.6 & 1.7 & 2 \\
\hline
\end{tabular}

Figure 5: Machine utilisation matrix and machine lower bounds

\section{DESIGNING FOR NON-INTERGROUPING MATERIAL HANDLING}

The classical cell grouping solution obtained in Figure 4 has not taken machine utilisation, cell sizes and exceptional elements into consideration. The single-pass heuristic parts [27] uses the machine utilisation matrix and machine lower bounds shown in Figure 5 to form the basis for resolving the problems. Parts are assigned in such a way that the number of machines required in a group does not exceed the upper limit of the number of machines decided by the management of the organisation. A new group is formed when the machine upper limit is violated or when a machine does not have the capacity for additional part. For upper limit of machine, $m_{u}=5$, the resource updates are shown in Table 3 and details of the steps in the allocation of parts for Figure 5 to a group are shown as follows: 
$\mathrm{i}=1$. Part 6 is assigned to group 1, taking along machines 1,3 and 8 . This imposes a utilisation of 0.3 on machines 1 and 3 , and a utilisation of 0.7 on machine 8. This leaves a slack of 0.7 for machines 1 and 3 and a slack of 0.3 on machine 8 as shown in Table 3.

$\mathrm{i}=2$. Part 2 fits into this group with no new machines required and, hence is added. The slack time is reduced to $0.1,0.5$ and 0 for machines 1,3 and 8 respectively.

$\mathrm{i}=3$. Part 9 goes into a new group because machine 8 does not have the capacity to handle the added load. The slack time is now $0.9,0.7,0.7$ and 0.8 for machines $1,3,8,2$ respectively.

$\mathrm{i}=4$. Part 7 will require two new machines if it were added to group 2, and this will exceed the allowable group size; hence, a new group is started. The slack time is now $0.8,0.7$ and 0.7 for machines 2,4 and 7 respectively.

$\mathrm{i}=5$. Part 10 fits into this group with no new machines required and, hence, is added. The slack time is reduced to $0.7,0.6$ and 0.5 respectively.

$\mathrm{i}=6$. Part 3 also fits into this group with no new machines required and, hence, is added. The slack time is reduced to $0.6,0.1$ and 0.4 respectively.

$\mathrm{i}=7$. Part 4 will require three new machines if it were added to group 3 , hence, a new group is started. The slack is now 0.8 for machines $5,6,9$ respectively.

$i=8$. Part 1 fits into this group with no new machine required. The slack time is reduced to $0.7,0.1$ and 0.3 for machines 5,6 and 9 .

i=9. Part 5 goes into a new group because machines 6 and 9 do not have the capacity to handle the added load. The slack is now $0.6,0.8$ and 0.4 for machines $5,6,9$.

$\mathrm{i}=10$. Part 8 fits into this group and slack is reduced to $0,0.2$ and 0 for machines $5,6,9$.

Table 3: Assignments using single-pass heuristic logic ( ${ }^{*}$ means inadequate capacity)

\begin{tabular}{|l|l|l|l|l|}
\hline Iteration & $\begin{array}{l}\text { Part } \\
\text { assigned }\end{array}$ & Group & $\begin{array}{l}\text { Machine } \\
\text { added }\end{array}$ & $\begin{array}{l}\text { Resource update } \\
\text { (machine,remaining time }\end{array}$ \\
\hline 1 & 6 & 1 & $1,3,8$ & $(1,0.7),(3,0.7),(8,0.3)$ \\
2 & 2 & 1 & - & $(1,0.1),(3,0.5),(8.0 .0)^{*}$ \\
\hline 3 & 9 & 2 & $1,3,8,2$ & $(1,0.9),(3,0.7),(8,0.7),(2,0.8)$ \\
\hline 4 & 7 & 3 & $2,4,7$ & $(2,0.8),(4,0.7),(7,0.7)$ \\
5 & 10 & 3 & - & $(2,0.7),(4,0.6),(7,0.5)$ \\
6 & 3 & 3 & - & $(2,0.6),(4,0.1),(7,0.4)$ \\
\hline 7 & 4 & 4 & $5,6,9$ & $(5,0.8),(6,0.8),(9,0.8)$ \\
8 & 1 & 4 & - & $(5,0.7),(6,0.1)^{*},(9,0.3)$ \\
\hline 9 & 5 & 5 & $5,6,9$ & $(5,0.6),(6,0.8),(9,0.6)$ \\
10 & 8 & 5 & - & $(5,0.0),(6,0.2),(9,0.0)$ \\
\hline
\end{tabular}

The new assignment shows that the number of machines required are 2 of machine $1 ; 2$ of machine $2 ; 2$ of machine $3 ; 1$ of machine $4 ; 2$ of machine $5 ; 2$ of machine $6 ; 1$ of machine $7 ; 2$ of machine 8 ; and 2 of machine 9. Machines 1,2 and 3 each exceed their lower bound by one (see Table 4). By applying the single-pass heuristic logic, it has been possible to deal with the intergroup move which would have occured when machine 2 produces part 9 , and also we have ascertained that the machine upper limit imposed by the management as well as machine capacities have been considered before the actual restructuring of the manufacturing system. 
Table 4: Capacity check

\begin{tabular}{|l|lllllllll|}
\hline \multicolumn{10}{|c|}{ Machine } \\
\hline & 1 & 2 & 3 & 4 & 5 & 6 & 7 & 8 & 9 \\
\hline $\begin{array}{l}\text { Lower } \\
\text { bound }\end{array}$ & 1 & 1 & 1 & 1 & 2 & 2 & 1 & 2 & 2 \\
\hline $\begin{array}{l}\text { Actual } \\
\text { no. used }\end{array}$ & 2 & 2 & 2 & 1 & 2 & 2 & 1 & 2 & 2 \\
\hline $\begin{array}{l}\text { Excess } \\
\text { required }\end{array}$ & 1 & 1 & 1 & 0 & 0 & 0 & 0 & 0 & 0 \\
\hline
\end{tabular}

\section{IMPLEMENTATION}

Now that the major manufacturing factors have been taken into consideration, the actual restruction of the jobshop into cells can commence. One machine each of types 1,2 and 3 may be purchased. There are other possibilities such as combining of groups. The systems engineer should explore various possibilities in consultation with management especially when suggesting the duplication of machines. Costs involved have to be considered at the point of implementation. The three cells of Figure 5 with additional machines resulting from the single-pass heuristic logic are shown in Figure 6.

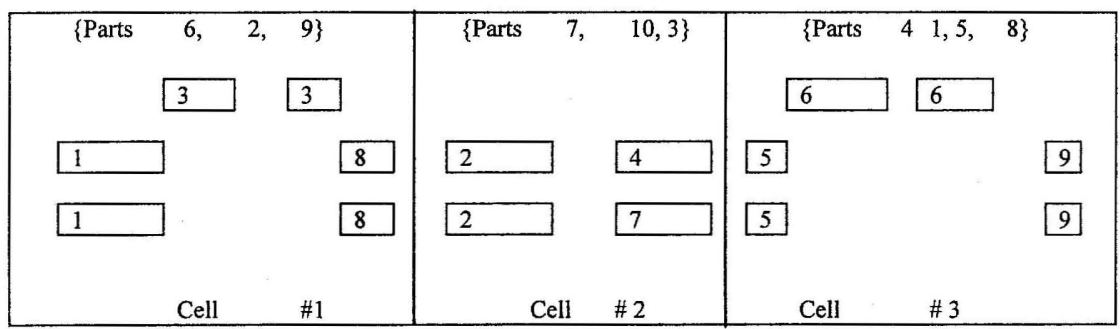

Figure 6: Final cells which consider different manufacturing constraints

\section{CONCLUSION}

Redesigning jobshop into manufacturing cells using classical GT clustering techniques for machines and parts do not take into consideration manufacturing factors such as machine utilisation, maximum number of machines allowed per group and intercellular moves during production of parts. The work reported here includes a preliminary grouping procedure, SOC; and a post processor which computes machine utilisation data together with minimum number of machines required, and a heuristic logic which assigns parts and advices on the actual number of machines required to meet practical manufacturing factors already mentioned. This extension to classical methods of cell formation has the advantage that the actual manufacturing system reconstruction from jobshop to manufacturing cells is reliable when implemented. 


\section{REFERENCES}

[1] Wemmerlov, U. And Hyer, N. L., "Cellular manufacturing in the US industry: a survey of user", International Journal of Production Research, Vol. 27, 1989, pp. 1511 -1530

[2] Wemmerlov, U. And Johnson, D. J., "Cellular manufacturing at 46 user plants : implementation experiences and performance improvements", International Journal of Production Research, Vol. 35, No. 1, 1997, pp. 29 - 49

[3] Bitran, G. R. and Hax, A. C. (1981), "On the design of hierarchical production planning systems", Decision Sciences, Vol. 8, pp. 717-743

[4] King, J. R. (1980), "Machine component grouping in production flow analysis: an approach using rank order clustering", International Journal of Production Research, Vol. 18, pp. 213-232

[5] Askin, R.G. and Subramanian, S. P. (1987), "A cost based heuristic for group technology configuration", International Journal of Production Research, Vol. 25 No.1, pp.101-113

[6] King, J. R. and Nakornchai, V. (1982), "Machine component group formation in group technology - review and extension", International Journal of Production Research, Vol. 20 pp. 117 133

[7] Chandrasekharan, M. P. and Rajagopalan, R. (1986a), "MODROC: an extension of rank order clustering for group technology", International Journal of Production Research, Vol. 24 No. 5, pp 1221-1233

[8] McCormick, W. T., Schweitzer, P. J., and White, T. W., "Problem decomposition and data reorganisation by a clustering technique", Operation Research, Vol. 20, 1972, pp. 993 - 1009

[9] McAuley, J., “Machine grouping for efficient production”, Production Engineer, Vol. 51, 1972 pp. 53

[10] De-Witte, J. (1980), "The use of similarity coefficients in production flow analysis", International Journal of Production Research, Vol. 18 No. 4, pp. 503-514

[11] Waghodekar, P. H., and Sahu, S., "Machine-component cell formation in group technology: MACE”, International Journal of Production Research, Vol. 22 No. 6, 1984, pp. 937 -948

[12] Seifoddini, H., and Wolfe, P. M., "Application of the similarity coefficient method in group technology", IIE Transactions, Vol. 18 No. 3, 1986, pp. 271 - 277

[13] Tam, K. Y., "An operation sequence based similarity coefficient for part families formations, "Journal of Manufacturing Systems", Vol. 9 No. 1, 1990, pp. 55 - 68

[14] MacQueen, J. B. (1967), "Some methods for classification and analysis of multivariate observations" Proceedings of the Fifth Symposium on Mathematical Statistics and Probability, University of California, Berkeley, Vol. 1, pp281 
[15] Chandrasekharan, M.P., and Rajagopalan, R., (1986b), "An ideal seed non-hierarchical clustering algorithm for cellular manufacturing", International Journal of Production Research, Vol. 24 No.2, pp. 451-464

[16] Chandrasekharan, M. P. and Rajagopalan, R. (1987), "ZODIAC- an algorithm for concurrent formulation of part families and machine cells", International Journal of Production Research, Vol. 26 No.6, pp. $835-850$

[17] Kusiak, A. (1987), "A generalised group technology concept", International Journal of Production Research, Vol. 25, pp. 561-569

[18] Srinivasan, G., Narendran, T. T., and Mahadevan, B., "An assignment model for the partfamilies problem in group technology", International Journal of Production Research, Vol. 28, No. 1,1990 , pp. $145-152$

[19] Kumar, K. R., Kusiak, A. and Vannelli, A. (1986), "Grouping of parts and components in flexible manufacturing systems", European Journal of Operational Research, Vol. 24 No. 2, pp. 387-397

[20] Mulvey, J. M., and Crowder, H. P., "Clustering analysis: an application of Lagrangian relaxation", Management Science, Vol. 25 No. 4, 1979, pp. 329 - 340

[21] Lenstra, (1974), "Clustering a data array and the travelling salesman problem", Operations Research, Vol. 22, pp. 413-414

[22] Ravikumar, K., Kusiak, A., and Vannelli, A., "Grouping of parts and components in flexible manufacturing systems", European Journal of Operational Research, Vol. 24, 1986, pp. 387-397

[23] Ballakur, A. and Steudel, H. J. (1987), “A within-cell utilisation based heuristic for designing cellular manufacturing systems", International Journal of Production Research, Vol. 25 No 5, pp. 639-665

[24] Tabucanon, M. T., and Ojha, R., "ICRMA - a heuristic approach for intercell flow reduction in cellular manufacturing systems", Material Flow, Vol. 4, 1987, pp. 189 - 197

[25] Kumar, K. R., and Vannelli, A. (1987), "Strategic subcontracting for efficient disaggregated manufacturing", International Journal of Production Research, Vol. 25 No. 12, pp. 1715 - 1728

[26] Onwubolu, G. C., "Redesigning jobshop to cellular manufacturing system", International Journal of Integrated Manufacturing Systems. Vol. 9, No. 6, 1998

[27] Askin, R.G., and Stanbridge, C.R., (1993), Modelling and analysis of manufacturing systems, John Wiley \& Sons, Inc. 